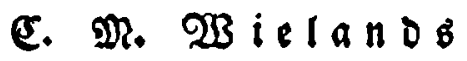

$\mathfrak{l} \mathfrak{d} \mathfrak{m} \mathfrak{m} \mathfrak{t} \mathfrak{i}$ 西e $\mathfrak{B} \mathfrak{e} \mathfrak{r} \mathfrak{E}$ Erper Bano.

รุerausgegeben

von

Э.

Poetifae werte I. Band.

\&eiplig,

jey Georg Joadia Gofden 2824. 


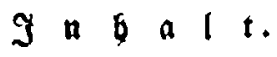

Die Ratur ber Ninge.

\section{Moralif̧e Briefe.}

